\title{
A Comprehensive Evaluation Approach to Measure Sustainable Development of Countries
}

\author{
Zhifeng Kong* \\ ${ }^{1}$ Institute of Mathematics and Statistics, Xi' an Jiaotong University, 710049, Xi'an, Shaanxi, China \\ ${ }^{*}$ Corresponding author
}

\begin{abstract}
Based on the quantitative definition of sustainable development, comprehensive evaluation method is used to estimate the level of a country's sustainable development. The indices chosen under four principles are divided into positive and negative indices after deliberate consideration. AHP is implied to determine the weights of indices. Two types of aggregated index are formed through two evaluation methods, and results show that the two methods prefer different types of countries. According to the difference, three types of sustainable development are defined: Backward, Unstable and Stable Sustainable Development. The aggregated index from the first method can help sort out the first two kinds of countries and regions, and that from the other method is able to help pick out the last two kinds.
\end{abstract}

Keywords-sustainable development; analytic hierarchy process; comprehensive evaluation method

\section{INTRODUCTION}

In 1987, a concept named "sustainable development" which soon became widely accepted, was defined on the Brundtland Commission as the "ability to ensure that the development meets the needs of the present without compromising the ability of future generations to meet their own needs. The 'environment' is where we live; and 'development' is what we all do in attempting to improve our lot within that abode. The two are inseparable." [1] Thus the description of sustainable development was interpreted as sustaining nature, life support and community while developing people, economy and society.

Sustainable development was measured by some indicators based on country or regional data, though determining the indicators and quantifying their influence is a laborious task which "needs to translate the uncertainties and arbitrariness of an infinitely complex world into a definite and preferably small set of quantitative indicators, or simply, numbers. As one might suspect, this is not easy to do." [2]

Many noble efforts have been made in the approaches, and their result reflects in the creation of various indicator initiatives. For instance, the UN established Commission on Sustainable Development (CSD) considering 58 different indicators [3]; the Genuine Progress Indicator (GPI) was created on the basis of consideration of 26 indicators by $\mathrm{C}$. Cobb et al [4]; and Ecological Footprint included discussion of 6 indicators traced annually from 1961 to 1999 [5].

\section{INDEX SELECTION AND STANDARDIZATION}

\section{A. Choosing Indices}

There are hundreds of indices available on various aspects of nations all over the globe. However, some data is not complete, and some indices are unrelated to sustainable development, so several principles are considered when choosing indices. (i) Only indices with data available on the internet will be chosen. (ii) Only indices which have strong relations with sustainable development will be taken into consideration. (iii) Only indices which have a certain level of diversity among nations will be taken into consideration. (iv) There are both positive indices and negative indices, and they are chosen separately.

Different from many models established by pioneers [1], some indicators of development evaluating consequences of human activity, though lead to degradation of environment, are considered as positive indices. The reason is that some kinds of human activities are unavoidable, for instance, mining. However as the advances of those activities have been made, they tend to lead to a higher efficiency on production, which means more output with same cost of environment. Moreover, effect on environment has been displayed on other indices of environment. To be rigorous, both negative and positive effects are taken into consideration determining weights of each of the indices.

Based on the principles above, 26 positive indices $\left(\mathrm{p}_{1}, \mathrm{p}_{2}, \cdots, \mathrm{p}_{26}\right)$ and 14 negative indices $\left(\mathrm{n}_{1}, \mathrm{n}_{2}, \cdots, \mathrm{n}_{14}\right)$ are selected. They belong to 6 groups $\left(\mathrm{C}_{1}, \mathrm{C}_{2}, \cdots, \mathrm{C}_{6}\right)$ : Health, Environment, Workforce, Education, Urban and Finance. For full details of all 40 indices, see appendix.

\section{B. Index Standardization and Elimination}

For each index, $x_{i}\left(x_{i} \geq 0\right)$ stands for the value of such index of the ith nation, and $\mathrm{x}=\left(\mathrm{x}_{1}, \mathrm{x}_{2}, \cdots, \mathrm{x}_{\mathrm{n}}\right)^{\mathrm{T}} \in \mathbb{R}^{\mathrm{n}}$ denotes the value vector of such index, where $n$ refers to the number of nations taken into consideration.

The linear method is one common way to do the standardization: $\hat{\mathrm{x}}=\left(\mathrm{x}-\mathrm{x}_{\min }\right) /\left(\mathrm{x}_{\max }-\mathrm{x}_{\min }\right)$, where $\mathrm{x}_{\text {min }}=\min _{1 \leq \mathrm{i} \leq \mathrm{n}} \mathrm{x}_{\mathrm{i}}, \mathrm{x}_{\max }=\max _{1 \leq \mathrm{i} \leq \mathrm{n}} \mathrm{x}_{\mathrm{i}}$. The linear method is selected since it ensures all the data being mapped into interval $[0,1]$.

Indices selected share importance to some extent, but when an index is similar in all the countries (regions), it is no more decisive in evaluating sustainable development. So these indices can be ignored to avoid large-scaled worthless 
modeling and calculation. Expectations of elimination in this model is that 20 positive indices and 12 negative indices are left at last, which can be modified if necessary.

Then the Least Mean Square Deviation method (LMSD) is utilized in elimination: For each index, calculate the mean square deviation of such index, then eliminate 6 positive indices which have least mean square deviations among all positive indices, and eliminate 2 negative indices by similar method. The eliminated indices are: $\mathrm{p}_{7}, \mathrm{p}_{15}, \mathrm{p}_{17}, \mathrm{p}_{20}, \mathrm{p}_{25}, \mathrm{p}_{26}, \mathrm{n}_{3}, \mathrm{n}_{4}$. Then rename the remaining indices as $\left(\mathrm{p}_{1}^{\prime}, \mathrm{p}_{2}^{\prime}, \cdots, \mathrm{p}_{20}^{\prime}\right)$ and $\left(\mathrm{n}_{1}^{\prime}, \mathrm{n}_{2}^{\prime}, \cdots, \mathrm{n}_{12}^{\prime}\right)$ according to the original order.

\section{QUANTIFY SUSTAINABLE DEVELOPMENT}

\section{A. Finding Weights}

Analytic Hierarchy Process (AHP) [7] is the method to find the weights of each index. Below is the hierarchy structure of positive indices and similar for negative indices.

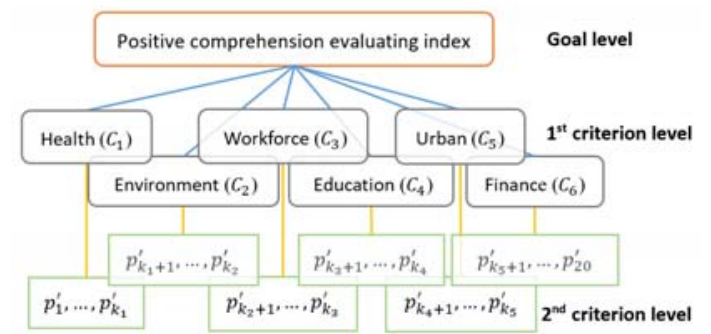

\section{FIGURE I. HIERARCHY STRUCTURE OF POSITIVE INDICES}

The next thing to do is to establish the judgment matrices. There are totally 13 judgment matrices: one (A) refers to the judgment matrix of the first criterion level to the goal, six $\left(A_{1}, A_{2}, \cdots, A_{6}\right)$ refer to 2 judgment matrices of the second criterion level to the first criterion level of positive indices and another six $\left(B_{1}, B_{2}, \cdots, B_{6}\right)$ refer to that of negative indices. According to the second principle introduced above, the difference among weights of the indices should not be too big. So the scale used in AHP is 1.0 1.9. Following is the value of judgment matrix $\mathrm{A}$ :

$$
A=\left(\begin{array}{cccccc}
1 & 1 / 1.2 & 1.4 & 1 & 1.3 & 1.2 \\
1.2 & 1 & 1.6 & 1.2 & 1.5 & 1.4 \\
1 / 1.4 & 1 / 1.6 & 1 & 1 / 1.3 & 1 & 1 / 1.2 \\
1 & 1 / 1.2 & 1.3 & 1 & 1.3 & 1.2 \\
1 / 1.3 & 1 / 1.5 & 1 & 1 / 1.3 & 1 & 1 \\
1 / 1.2 & 1 / 1.4 & 1.2 & 1 / 1.2 & 1 & 1
\end{array}\right)
$$

The consistency proportion CR of judgment matrix A is $0.0004<0.1$, which shows that $A$ is proper. For values and consistency proportions of other 12 judgment matrices, see appendix.

Then the weight vector of positive (negative) indices to the positive (negative) evaluation function can be directly acquired as $w_{p} \in \mathbb{R}^{20}\left(w_{n} \in \mathbb{R}^{12}\right)$ through the 13 judgment matrices by using the standard AHP method [7]. Values of $w_{p}$ and $w_{n}$ are (index in sequence):

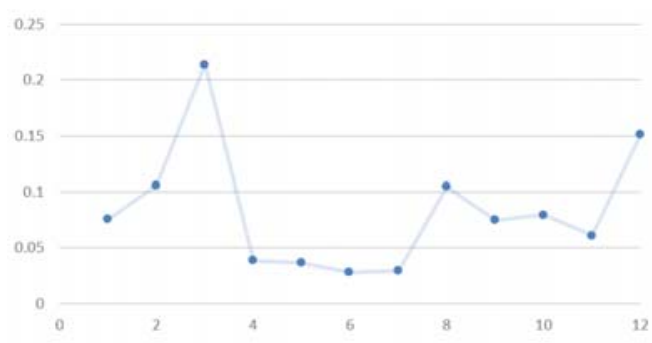

FIGURE II. VALUES OF $\mathrm{w}_{\mathrm{p}}$

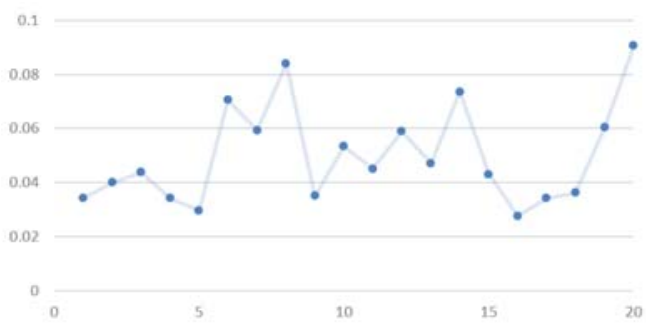

FIGURE III. VALUES OF $\mathrm{w}_{\mathrm{n}}$

\section{B. Index Aggregation}

Two methods: LWCA (Linear Weighted Comprehensive Assessment method) and TOPSIS (Technique for Order Preference by Similarity to Ideal Solution), are used separately to get aggregated index, resulting in acknowledgment of two different values $I_{i}$ and $I_{i}^{\prime}$. Suppose country i has complete values on the 20 positive indices $\left(\mathrm{p}^{\mathrm{i}} \in \mathbb{R}^{20}\right)$ and 12 negative indices $\left(\mathrm{n}^{\mathrm{i}} \in \mathbb{R}^{12}\right)$, then the two methods are shown below:

- LWCA: It directly contrasts the positive side and the negative side:

$$
I_{i}=\frac{w_{p}^{T} p^{i}}{w_{n}^{T} n^{i}}=\frac{\sum_{j=1}^{20} w_{p}(j) p^{i}(j)}{\sum_{j=1}^{12} w_{n}(j) n^{i}(j)}
$$

- TOPSIS: It measures the distance between the current condition of the country and the ideal state, where values of all positive indices are 1 and those of negative indices are 0 :

$$
I_{i}^{\prime}=\left(\sum_{j=1}^{20} w_{p}(j)\left(p^{i}(j)-1\right)^{2}+\sum_{j=1}^{12} w_{n}(j)\left(n^{i}(j)-1\right)^{2}\right)^{-1}
$$

In 2013, developed countries makes a percentage of $25.13 \%$ of all countries (regions) participating statistics [8], so assume that the sustainable countries (regions) also make $25.13 \%$ of all Sorting countries (regions) by their Is and I's, the last among sustainable ones is determined as the threshold.

Top rankings including 20 countries (regions) and bottom rankings including 10 countries (regions) are listed in Table 1. Then the threshold countries and indices value are found, shown in Table 2. Details of these two tables are in Appendix. 


\section{ANALYSIS}

Table 1 illustrates that countries (regions) in top rankings of I got through LWCA appear to be those with no or little heavy industry and low consumption of resources and those in the Middle East. Additionally, most of them have poor territory. This is a reasonable outcome of LWCA, for the aggregated index is calculated through positive comprehensive evaluation index divided by negative comprehensive evaluation index, and the latter is made up with pollution from heavy industries, consumption of natural resources and per-capita indices (especially advantageous for small countries in territories). Therefore 4those countries, together with countries heavily rely on the income of resources export, have very small denominator in the evaluating function and eventually get higher evaluation than many developed countries. The development status of former countries is called Backward Sustainable Development (BSD) - slow-paced development with hardly any damage to the environment, which is undoubtedly sustainable. (Features see in the table below) As for the latter countries which heavily rely on resources export, e.g. Kuwait and UAE, their development status is called Unstable Sustainable Development (USD) - "illusion" of sustainable development (e.g. constant oil production every year) with high risk of rapid collapse (e.g. oil production of dried field). For Kuwait and UAE, what if the resources dry up? They should immediately launch transformation, in order to avoid the possible impacts on resource problems. In a word, the aggregated index calculated through LWCA place emphasis on sustainability.

From Table 1, countries (regions) in top rankings of I0 aggregated index calculated through TOPSIS are mostly developed countries in Europe. The reason to get a different outcome compared with the former method is that the negative indices are not treated as denominator anymore, instead, they are summed up. As a result, this evaluation index place emphasis on degree of development, because positive indices are $67 \%$ more than negative indices in amount and calculating Euclidean distance enlarges the deviation in influence of final result between positive and negative indices. In this case, developed countries (regions) with high-leveled industries and technologies have dominating advantages, such as a high value in the indicator "GDP per unit of energy use"(value of this indicator in Hong Kong of China is 4.86 times the value in
China mainland [9]) which enables them produce enormous wealth while consuming not much. Their development status is called Stable Sustainable Development (SSD). (Features see table above).

Table 1 also illustrates that the countries (regions) with USD status are the only ones that have high rankings under different evaluation emphasis. It is implied from this phenomenon that the USD status is the transitional status from BSD to SSD.

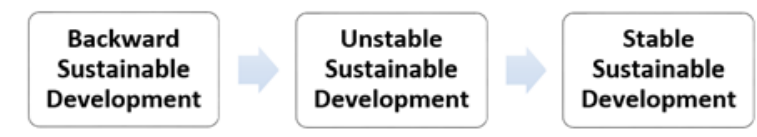

\section{FIGURE IV. RELATIONSHIP OF THREE STATUS OF SUSTAINABLE DEVELOPMENT}

\section{ACKNOWLEDGMENT}

I would like to thank Professor Yicang Zhou, who was my teacher on mathematical modeling. Without his lectures, I would not be able to think about problems about applied mathematics.

\section{REFERENCES}

[1] Kates, Robert W., Thomas M. Parris, and Anthony A. Leiserowitz. What is sustainable Development: Goals indicators, values, and practice. Environment: Science and Policy for Sustainable Development, 2005, 47(3): 8-21.

[2] Branko Milicevic. Book Reviews. Natural Resources Forum, 2008, 32: 351-352.

[3] United Nations Division of Sustainable Development. Indicators of Sustainable Development: Guidelines and Methodologies. 2001.

[4] C. Cobb, et al. The Genuine Progress Indicator 2000 Update. Oakland, CA: Redefining Progress, 2000.

[5] M. Wackernagel, C. Monfreda, and D. Deumiing. Ecological Footprint of Nations: November 2002 Update. Oakland, CA: Redefining Progress, 2002.

[6] World Commission on Environment and Development (WCED). Our Common Future. New York: Oxford University Press, 1987: 8.

[7] Wikipedia. Analytic hierarchy process- Wikipedia, the free encyclopedia http://en.wikipedia. org/wiki/Analytic_hierarchy_process

[8] Mi'er BBS. There are 47 developed countries in 2013, which surprised Chinese. http://bbs.miercn. com/201307/thread_210959_1.html

[9] World Bank. Indicators | Data. http://data.worldbank.org/indicator/all.

\section{APPENDIX}

Below is Table of countries or regions with the highest and lowest value of aggregated indices.

TABLE I. COUNTRIES (REGIONS) WITH THE HIGHEST AND LOWEST VALUE OF AGGREGATED INDEX

\begin{tabular}{c|cc|cc}
\hline \multirow{2}{*}{ Ranking } & \multicolumn{2}{|c}{ LWCA } & \multicolumn{2}{c}{ TOPSIS } \\
\cline { 2 - 5 } & Countries (Regions) & $I$ & Countries (Regions) & $I^{\prime}$ \\
\hline 1 & San Marino & 2634.235 & Sweden & 4.281314 \\
2 & Monaco & 2371.222 & Norway & 3.898829 \\
3 & Andorra & 925.5979 & Finland & 3.764083 \\
4 & American Samoa & 610.3015 & Kuwait & 3.369426 \\
5 & Cayman Islands & 373.8311 & Iceland & 3.142231 \\
6 & Palau & 153.5057 & Costa Rica & 2.998307
\end{tabular}




\begin{tabular}{|c|c|c|c|c|c|c|}
\hline & Turks and & Turks and Caicos Islands & 137.6472 & \multicolumn{2}{|c|}{ Seychelles } & 2.963683 \\
\hline & Sint Maar & Sint Maarten (Dutch part) & 98.79866 & \multicolumn{2}{|c|}{ France } & 2.950987 \\
\hline & Northern & Northern Mariana Islands & 59.42375 & \multicolumn{2}{|c|}{ Oman } & 2.888266 \\
\hline & \multicolumn{2}{|c|}{ Tuvalu } & 29.4201 & \multicolumn{2}{|c|}{ Bahamas, The } & 2.860301 \\
\hline & Pacific isl & Pacific island small states & 25.28996 & \multicolumn{2}{|c|}{ Switzerland } & 2.849595 \\
\hline & 12 & Kuwait & 21.75739 & \multicolumn{2}{|c|}{ Guyana } & 2.828708 \\
\hline & Mars & Marshall Islands & 21.7335 & \multicolumn{2}{|c|}{ Denmark } & 2.794578 \\
\hline & $\begin{array}{r}\text { Un } \\
\text { Emir }\end{array}$ & $\begin{array}{c}\text { United Arab } \\
\text { Emirates(UAE) }\end{array}$ & 21.25511 & \multicolumn{2}{|c|}{ Suriname } & 2.777231 \\
\hline & 15 & Greenland & 20.4204 & \multicolumn{2}{|c|}{ Cabo Verde } & 2.758934 \\
\hline & Antigua & Antigua and Barbuda & 15.27164 & \multicolumn{2}{|c|}{ UAE } & 2.740371 \\
\hline & Micron & Micronesia, Fed. Sts. & 15.00409 & \multicolumn{2}{|c|}{ Slovenia } & 2.693649 \\
\hline & 18 & Dominica & 12.69345 & \multicolumn{2}{|c|}{ Belgium } & 2.640722 \\
\hline & 19 & Grenada & 10.07641 & \multicolumn{2}{|c|}{ Belize } & 2.614173 \\
\hline & Solor & Solomon Islands & 9.684683 & \multicolumn{2}{|c|}{ Bhutan } & 2.60677 \\
\hline$\vdots$ & $\vdots$ & $\vdots$ & \multicolumn{3}{|l|}{ serese } & \\
\hline 239 & Bosnia and Herzegovina & 0.947587 & Sol & & 1.101075 & \\
\hline 240 & Somalia & 0.939788 & Faero & & 1.086949 & \\
\hline 241 & Yemen, Rep. & 0.904898 & Turks and $\mathrm{C}$ & ands & 1.076444 & \\
\hline 242 & South Africa & 0.89214 & & & 1.072777 & \\
\hline 243 & Haiti & 0.853117 & St. Martin & art) & 1.030178 & \\
\hline 244 & Iraq & 0.79115 & Isle & & 1.029617 & \\
\hline 245 & Libya & 0.781795 & Sint Maarte & part) & 1.028382 & \\
\hline 246 & Channel Islands & 0.533914 & Chann & & 1.002103 & \\
\hline 247 & Curacao & 0.417934 & $\mathrm{Cu}$ & & 0.99506 & \\
\hline 248 & Kosovo & 0.297477 & & & 0.93076 & \\
\hline
\end{tabular}

Below is Table of threshold countries and indices values.

TABLE II. THRESHOLD COUNTRIES AND INDICES VALUE

\begin{tabular}{c|ccc}
\hline Method & Ranking & Country (Region) & Threshold \\
\hline LWCA & 62 & Finland & $I=3.064507$ \\
TOPSIS & 62 & Bolivia & $I^{\prime}=2.067360$ \\
\hline
\end{tabular}

Below is Table of three sustainable status with their features and typical countries.

TABLE III. HREE SUSTAINABLE DEVELOPMENT STATUS WITH THEIR FEATURES AND EXAMPLE COUNTRIES

\begin{tabular}{c|c|c}
\hline Status & Features & Examples \\
\hline Backward Sustainable & Low-leveled industries and techs, & San Marino \\
Development (BSD) & agriculture-dominated economy & Andorra \\
\hline Unstable Sustainable & Low-leveled industries and techs, & Kuwait \\
Development (USD) & resources-depended economy & UAE \\
\hline Stable Sustainable & High-leveled industries and techs & Sweden \\
Development (SSD) & & Norway
\end{tabular}

Full details of all 40 indices (26 positive and 14 negative ones) are in Tables 4 and 5, where red rows refer to eliminated indices.

TABLE IV. POSITIVE INDICES

\begin{tabular}{ccc|c}
\hline Group & Group Name & ID & Name \\
\hline$C_{1}$ & Health & $p_{1}$ & Health expenditure, total (\% of GDP) \\
$C_{1}$ & Health & $p_{2}$ & Immunization, measles (\% of children ages 12-23 months) \\
$C_{1}$ & Health & $p_{3}$ & Improved sanitation facilities, urban (\% of urban population with access) \\
$C_{1}$ & Health & $p_{4}$ & Health expenditure, public (\% of total health expenditure) \\
$C_{1}$ & Health & $p_{5}$ & Life expectancy at birth, total (years) \\
$C_{2}$ & Environment & $p_{6}$ & Forest area (\% of land area) \\
$C_{2}$ & Environment & $p_{7}$ & Energy use (kg of oil equivalent per capita) \\
$C_{2}$ & Environment & $p_{8}$ & Total natural resources rents (\% of GDP)
\end{tabular}




$\begin{array}{ccc}C_{2} & \text { Environment } & p_{9} \\ C_{3} & \text { Workforce } & p_{1} \\ C_{3} & \text { Workforce } & p_{1} \\ C_{3} & \text { Workforce } & p_{1} \\ C_{4} & \text { Education } & p_{1} \\ C_{4} & \text { Education } & p_{1} \\ C_{4} & \text { Education } & p_{1} \\ C_{4} & \text { Education } & p_{1} \\ C_{4} & \text { Education } & p_{1} \\ C_{5} & \text { Urban } & p_{1} \\ C_{5} & \text { Urban } & p_{1} \\ C_{5} & \text { Urban } & p_{2} \\ C_{5} & \text { Urban } & p_{2} \\ C_{5} & \text { Urban } & p_{2} \\ C_{6} & \text { Finance } & p_{23} \\ C_{6} & \text { Finance } & p_{2} \\ C_{6} & \text { Finance } & p_{2} \\ C_{6} & \text { Finance } & p_{2}\end{array}$

Improved water source, rural ( $\%$ of rural population with access)

Proportion of seats held by women in national parliaments (\%)

GDP per person employed (constant 1990 PPP \$)

Employment to population ratio, 15+, total (\%) (modeled ILO estimate)

Public spending on education, total (\% of GDP)

School enrollment, secondary (\% gross)

Technicians in R\&D (per million people)

School enrollment, primary (\% net)

High-technology exports ( $\%$ of manufactured exports)

Improved water source, urban ( $\%$ of urban population with access) Urban population ( $\%$ of total)

Mobile cellular subscriptions (per 100 people) Internet users (per 100 people)

Motor vehicles (per 1,000 people) GDP per capita (current US\$)

Services, etc., value added (\% of GDP)

Cash surplus/deficit ( $\%$ of GDP) Gross savings ( $\%$ of GDP)

TABLE V. NEGATIVE INDICES

\begin{tabular}{ccc|c}
\hline Group & Group Name & ID & Name \\
\hline$C_{1}$ & Health & $n_{1}$ & Incidence of tuberculosis (per 100,000 people) \\
$C_{1}$ & Health & $n_{2}$ & Population ages 65 and above (\% of total) \\
$C_{2}$ & Environment & $n_{3}$ & $C O_{2}$ emissions (kt) \\
$C_{2}$ & Environment & $n_{4}$ & GDP per unit of energy use (constant 2011 PPP \$ per kg of oil equivalent) \\
$C_{2}$ & Environment & $n_{5}$ & Fossil fuel energy consumption (\% of total) \\
$C_{3}$ & Workforce & $n_{6}$ & Unemployment, female (\% of female labor force) (modeled ILO estimate) \\
$C_{3}$ & Workforce & $n_{7}$ & Unemployment, male (\% of male labor force) (modeled ILO estimate) \\
$C_{3}$ & Workforce & $n_{8}$ & Vulnerable employment, female (\% of female employment) \\
$C_{3}$ & Workforce & $n_{9}$ & Vulnerable employment, male (\% of male employment) \\
$C_{4}$ & Education & $n_{10}$ & Unemployment, total (\% of total labor force) (modeled ILO estimate) \\
$C_{4}$ & Education & $n_{11}$ & Prevalence of HIV, total (\% of population ages 15-49) \\
$C_{5}$ & Urban & $n_{12}$ & $C O_{2}$ emissions from residential buildings and \\
& & & commercial and public services (million metric tons) \\
$C_{5}$ & Urban & $n_{13}$ & Urban poverty headcount ratio at national poverty lines \\
$C_{6}$ & Finance & $n_{14}$ & Total debt service (\% of exports of goods, services and primary income) \\
\hline
\end{tabular}

Values of other 12 judgment matrices are shown below, and the consistency proportions are shown in Table 6.

$$
\begin{aligned}
& A_{1}=\left(\begin{array}{ccccc}
1 & 1 / 1.3 & 1 / 1.2 & 1 & 1.2 \\
1.3 & 1 & 1 / 1.2 & 1.2 & 1.3 \\
1.2 & 1.2 & 1 & 1.3 & 1.4 \\
1 & 1 / 1.2 & 1 / 1.3 & 1 & 1.2 \\
1 / 1.2 & 1 / 1.3 & 1 / 1.4 & 1 / 1.2 & 1
\end{array}\right), A_{2}=\left(\begin{array}{ccc}
1 & 1.2 & 1 / 1.2 \\
1 / 1.2 & 1 & 1 / 1.4 \\
1.2 & 1.4 & 1
\end{array}\right), A_{3}=\left(\begin{array}{ccc}
1 & 1 / 1.5 & 1 / 1.3 \\
1.5 & 1 & 1.2 \\
1.3 & 1 / 1.2 & 1
\end{array}\right) \\
& A_{4}=\left(\begin{array}{ccc}
1 & 1.3 & 1 / 1.3 \\
1 / 1.3 & 1 & 1 / 1.5 \\
1.3 & 1.5 & 1
\end{array}\right), A_{5}=\left(\begin{array}{cccc}
1 & 1.5 & 1.3 & 1.2 \\
1 / 1.5 & 1 & 1 / 1.2 & 1 / 1.4 \\
1 / 1.3 & 1.2 & 1 & 1 \\
1 / 1.2 & 1.4 & 1 & 1
\end{array}\right), A_{6}=\left(\begin{array}{cc}
1 & 1 / 1.5 \\
1.5 & 1
\end{array}\right) \\
& B_{1}=B_{4}^{T}=\left(\begin{array}{cc}
1 & 1 / 1.4 \\
1.4 & 1
\end{array}\right), B_{2}=B_{6}=(1), B_{3}=\left(\begin{array}{cccc}
1 & 1.1 & 1.3 & 1.3 \\
1 / 1.1 & 1 & 1.3 & 1.3 \\
1 / 1.3 & 1 / 1.3 & 1 & 1 / 1.1 \\
1 / 1.3 & 1 / 1.3 & 1.1 & 1
\end{array}\right), B_{5}=\left(\begin{array}{cc}
1 & 1.3 \\
1 / 1.3 & 1
\end{array}\right)
\end{aligned}
$$

TABLE VI. TABLE 6: CONSISTENCY PROPORTIONS OF 12 JUDGMENT MATRICES

\begin{tabular}{c|cccccccccccc}
\hline Matrix & $A_{1}$ & $A_{2}$ & $A_{3}$ & $A_{4}$ & $A_{5}$ & $A_{6}$ & $B_{1}$ & $B_{2}$ & $B_{3}$ & $B_{4}$ & $B_{5}$ & $B_{6}$ \\
\hline$C R$ & 0.0014 & 0 & 0.0002 & 0.0015 & 0.0010 & 0 & 0 & 0 & 0.0008 & 0 & 0 & 0 \\
\hline
\end{tabular}

